\title{
BCSG1 siRNA delivered by lentiviral vector suppressed proliferation and migration of MDA-MB-231 cells
}

\author{
JIN-SONG HE ${ }^{1,2^{*}}$, NI XIE ${ }^{3 *}$, JIAN-BO YANG ${ }^{4}$, HONG GUAN $^{5}$, WEI-CAI CHEN ${ }^{2}$, CHANG ZOU $^{6}$, \\ YI-WEN OUYANG ${ }^{2}$, YOU-SHENG MAO ${ }^{2}$, XUE-YING LUO ${ }^{2}$, YUE PAN $^{2}$ and $\mathrm{LI} \mathrm{FU}^{7 *}$ \\ ${ }^{1}$ Department of Breast Surgery, Peking University Shenzhen Hospital; ${ }^{2}$ Department of Breast Surgery and ${ }^{3}$ Biobank, \\ The First Affiliated Hospital of Shenzhen University, Second People's Hospital of Shenzhen, Shenzhen, \\ Guangdong 518035, P.R. China; ${ }^{4}$ Department of Laboratory Medicine and Pathology, Masonic Cancer Center, \\ University of Minnesota, MN Twin Cities, MN 55455, USA; ${ }^{5}$ Department of Pathology, \\ The First Affiliated Hospital of Shenzhen University, Second People's Hospital of Shenzhen, Shenzhen, \\ Guangdong 518035; ${ }^{6}$ Clinical Research Centre, Shenzhen People's Hospital, Shenzhen, Guangdong 518020; \\ ${ }^{7}$ Cancer Research Centre, School of Medicine, Shenzhen University, Shenzhen, Guangdong 518060, P.R. China
}

Received November 2, 2016; Accepted December 13, 2017

DOI: $10.3892 /$ ijmm.2017.3355

\begin{abstract}
Breast cancer-specific gene 1 (BCSG1), also referred to as $\gamma$-synuclein (SNCG), is highly expressed in human infiltrating breast carcinomas, but not in normal or benign breast tissue. The present study aimed to evaluate the effects of BCSG1 siRNA delivered by lentiviral vector on breast cancer cells and investigate the underlying mechanisms. BCSG1 RNAi lentiviral vector was constructed and transfected into MDA-MB-231 cells. BCSG1 mRNA levels were determined by quantitative polymerase chain reaction analysis. Cell proliferation, migration and apoptosis were evaluated by using the Cell Counting Kit-8, Transwell assay and flow cytometry, respectively, followed by western blotting to determine the relative levels of AKT, extracellular signal-regulated kinase (ERK), p-AKT and p-ERK expression. BCSG1 mRNA levels were significantly reduced in MDA-MB-231 cells following transfection of BCSG1 siRNA delivered by lentiviral vector. Cell migration and proliferation were significantly decreased and the cell cycle was arrested. Western blot analysis indicated that the protein levels of p-AKT and p-ERK were significantly lower in the BCSG1 siRNAtreated groups compared with the control and negative control groups. Therefore, BCSG1 siRNA delivered by lentiviral vector
\end{abstract}

Correspondence to: Dr Jin-Song He, Department of Breast Surgery, Peking University Shenzhen Hospital, 1120 LianHua Road, FuTian District, Shenzhen, Guangdong 518035, P.R. China

E-mail: hejinsong1968@126.com

Dr Li Fu, Cancer Research Centre, School of Medicine, Shenzhen University, 3688 NanHai Road, NanShan District, Shenzhen, Guangdong 518060, P.R. China

E-mail: gracelfu@szu.edu.cn

${ }^{*}$ Contributed equally

Key words: breast cancer, breast cancer-specific gene 1, small interfering RNA, lentiviral vector was able to significantly reduce BCSG1 expression, suppress cell migration and proliferation, possibly through the reduction of the protein levels of p-AKT and p-ERK.

\section{Introduction}

Breast cancer is the most common type of cancer and the second leading cause of cancer-related mortality in women $(1,2)$. Although several effective options, including radiation, chemotherapy, endocrine therapy and surgery, may be selected for treatment, the mortality rate of breast cancer remains high. Numerous studies have been conducted to investigate the pathogenesis of breast cancer; however, the precise mechanism remains unclear. Genetic alterations in normal cells are considered to be involved in the occurrence of breast cancer.

Breast cancer-specific gene 1 (BCSG1) is not expressed in normal breast tissue or benign breast diseases, but is highly expressed in human infiltrating breast carcinomas, and its expression is stage-specific (3-5). When overexpressed, BCSG1 leads to a significant increase in the proliferation, invasiveness and metastasis of breast cancer cells (6), whereas downregulation of BCSG1 expression sensitizes breast cancer cells to antimicrotubule agent-induced cytotoxicity (7-9). These findings indicate that BCSG1 may act as a tumor marker, and downregulation of BCSG1 may be an effective strategy in breast cancer treatment.

As a type of retrovirus, lentiviral vectors can infect both dividing and non-dividing cells due to their preintegration complex (virus 'shell') $(10,11)$. It has been reported that lentiviruses can change the expression levels of target genes for up to 6 months (12); thus, it possible to provide highly effective gene therapy by using lentiviruses. These properties make lentiviral vectors attractive vehicles for delivering small interfering RNAs (siRNAs) into mammalian cells $(13,14)$.

RNA interference (RNAi) inhibits gene expression by reducing mRNA stability or inhibiting translation (15). Since the discovery of siRNA in gene silencing (16), RNAi has become 
a powerful research tool in gene function studies. Compared with genetic deletion, RNAi-mediated gene silencing has several advantages (17). Numerous studies have demonstrated the applications of RNAi in cancer research $(18,19)$. In the present study, a BCSG1 RNAi lentiviral vector was initially constructed, followed by transfection of MDA-MB-231 breast cancer cells. The proliferation, migration and apoptosis of MDA-MB-231 cells were then evaluated and the underlying mechanisms were investigated.

\section{Material and methods}

Cell lines. The 293T cell line was selected for lentivirus packaging and titer determination, while the human breast cancer line MDA-MB-231 was used for functional experiments. All the cells were purchased from American Type Culture Collection (Manassas, VA, USA) and were cultured in Dulbecco's modified Eagle's medium (Gibco; Thermo Fisher Scientific, Carlsbad, CA, USA) supplemented with $10 \%$ heat-inactivated fetal bovine serum, $100 \mathrm{mg} / / 1$ streptomycin and $100 \mathrm{U} / / \mathrm{ml}$ penicillin (Gibco; Thermo Fisher Scientific) under $5 \% \mathrm{CO}_{2}$, at $37^{\circ} \mathrm{C}$ in a humidified incubator.

Construction of the BCSG1 RNAi lentiviral vector. Based on the gene sequence of BCSG1 in GenBank (Gene ID: 6623), primers of BCSG1 siRNA and negative control were designed and cloned into a PGLV3//H1//GFP + Puro vector. The interference primers for BCSG1 (Si-BCSG1) were as follows: Forward, 5'-GATCCGCCCACTTATGCTGCTGTGAATTTCAAGAGA ATTCACAGCAGCATAAGTGGGCTTTTTTG-3' and reverse, 5'-AATTCAAAAAAGCCCACTTATGCTGCTGTGAAT TCTCTTGAAATTCACAGCAGCATAAGTGGGCG-3'. The primers for the interference negative control (NC) were as follows: Forward, 5'-GATCCGTTCTCCGAACGTGTCACG TTTCAAGAGAACGTGACACGTTCGGAGAACTTTTTT G-3' and reverse, 5'-GTTCTCCGAACGTGTCACGTTTCA AGAGAACGTGACACGTTCGGAGAACTT-3'. Cell transformation and plasmid sequencing of positive cell clones were used to confirm the successful construction of the lentiviral vector.

Lentivirus packaging and titer determination. After reaching a confluence of $\sim 70-80 \%, 293 \mathrm{~T}$ cells were transfected with NC and BCSG1 RNAi lentiviral vectors. After $48 \mathrm{~h}$, the viruses were harvested and concentrated, and their titers were detected. MDA-MB-231 cells at a confluence of $~ 90 \%$ were transfected with NC lentivirus (NC group), BCSG1 lentivirus siRNA (siRNA group) or not transfected (control group). Lipofectamine 2000 (Invitrogen; Thermo Fisher Scientific, Carlsbad, CA, USA) was used for transfection according to the manufacturer's instructions.

Quantitative polymerase chain reaction ( $q P C R)$. Total RNA was extracted from MDA-MB-231 cells and the quality was evaluated by agarose gel electrophoresis. The concentration of the extracted RNA was estimated by optical density measurement (A260//A280 ratio) with the Q5000 Spectrophotometer (Quawell, Sunnyvale, CA, USA). qPCR was then performed using the SYBR-Green-based PCR master mix. The ABI PRISM 7500 system (ABI, Grand Island, NY, USA) was used for all amplification reactions in a total volume of $25 \mu \mathrm{l}$.
The cycling conditions were as follows: an initial $10 \mathrm{~min}$ of pre-denaturation at $95^{\circ} \mathrm{C}$, followed by 40 cycles of $95^{\circ} \mathrm{C}$ for $10 \mathrm{sec}, 60^{\circ} \mathrm{C}$ for $20 \mathrm{sec}$, and $72^{\circ} \mathrm{C}$ for $15 \mathrm{sec}$. The specificity of the amplification products was confirmed by melting curve analysis. All products were normalized to $\beta$-actin mRNA levels. Each specimen was repeated 3 times.

CCK- 8 assay. At $72 \mathrm{~h}$ after transfection, MDA-MB-231 cells were seeded in the 96 -well plates at a density of 2,000 cells/well and incubated for $0,24,48$ and $72 \mathrm{~h}$. At the end of the incubation, $20 \mu \mathrm{l}$ CCK-8 (Dojindo Molecular Technologies, Inc., Xiongben, Japan) were added to each well. The plates were then incubated in a humidified incubator at $37^{\circ} \mathrm{C}$ under $5 \% \mathrm{CO}_{2}$ for $1 \mathrm{~h}$, and the absorbance was measured at $450 \mathrm{~nm}$.

Transwell assay. After $72 \mathrm{~h}$ of transfection, MDA-MB-231 cells were seeded in the 6-well Transwell upper chambers at a density of 25,000 cells/well. The Transwell assay was performed according to the manufacturer's instructions. The Transwell chambers were then incubated for $48 \mathrm{~h}$ at $37^{\circ} \mathrm{C}$ in a humidified incubator with $5 \% \mathrm{CO}_{2}$, and then the lower chamber was stained with hematoxylin and photographed.

Flow cytometry analyses. MDA-MB-231 cells in the logarithmic phase of grow th were seeded in 6-well plates at a density of 500,000 cells/well and incubated overnight. After $72 \mathrm{~h}$ of transfection, the cells were collected, washed with Dulbecco's phosphate-buffered saline (DPBS; Genview, El Monte, CA, USA), fixed in $70 \%$ ethanol, and incubated overnight at $-20^{\circ} \mathrm{C}$; ethanol was then removed by centrifugation at 3,000 $\mathrm{x}$ g. The cell pellets were washed with DPBS, followed by incubation with $100 \mu \mathrm{l}$ propidium iodide (PI) solution (Sigma-Aldrich; Merck KGaA, St. Louis, MO, USA) for 5-10 min in the dark at $37^{\circ} \mathrm{C}$ and were then analyzed by flow cytometry (Beckman Coulter, Brea, CA, USA).

Flow cytometeric analysis for apoptosis was performed using an Annexin V-FITC apoptosis detection kit (Shanghai Genechem Biotech Co., Ltd., Shanghai, China) and PI. Cells were harvested $72 \mathrm{~h}$ after transfection, followed by staining with the binding buffer, $5 \mu \mathrm{l}$ Annexin V/ fluorescein isothiocyanate (FITC) for $15 \mathrm{~min}$ in the dark at room temperature. PI was then added and incubated in the dark at room temperature for a further $15 \mathrm{~min}$. Apoptosis was then detected by flow cytometry.

Western blotting. Cell lysates were harvested and samples (50 $\mu \mathrm{g}$ protein/lane) were fractionated by $12 \%$ sodium dodecyl sulfate-polyacrylamide gel electrophoresis and transferred to polyvinylidene fluoride membranes. The membranes were incubated in 5\% skimmed milk for $1 \mathrm{~h}$ at room temperature, and overnight at $4{ }^{\circ} \mathrm{C}$ with primary antibodies; glyceraldehyde 3-phosphate dehydrogenase was used as the control. The bands were visualized using an ECL chemiluminescence kit (Genview) and quantitated by Quantity One (Bio-Rad, Hercules, CA, USA).

\section{Results}

BCSG1 mRNA level in MDA-MB-231 cells. As shown in Fig. 1A, the levels of BCSG1 mRNA were found to be significantly lower in the siRNA group compared with those in the NC $(\mathrm{P}<0.0001)$ and control groups $(\mathrm{P}<0.0001)$. These 

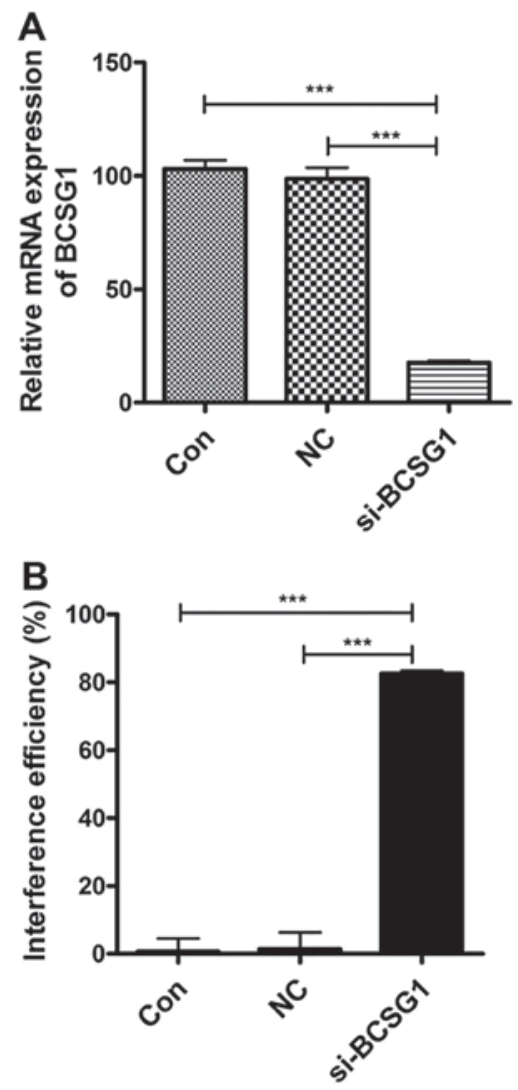

Figure 1. The relative concentration of breast cancer-specific gene 1 (BCSG1) mRNA in the human breast cancer cell line MDA-MB-231. (A) Relative mRNA expression of BCSG1. (B) Interference efficiency of BCSG1 lentivirus siRNA. ${ }^{* * *} \mathrm{P}<0.0001$. NC, negative control.

results suggest that BCSG1 lentivirus siRNA significantly downregulated the BCSG1 mRNA levels in breast cancer cells; the interference efficiency reached $82.45 \%$ (Fig. 1B).

Proliferation of MDA-MB-231 cells. The CCK-8 assay demonstrated that cell proliferation decreased significantly in the siRNA group $(\mathrm{P}<0.0001)$, particularly after $72 \mathrm{~h}$ of treatment; no significant difference was observed between the $\mathrm{NC}$ and control groups ( $\mathrm{P}>0.05$; Fig. 2). The CCK- 8 assay demonstrated that BCSG1 lentivirus siRNA inhibited the proliferation of breast cancer cells.

Migration of MDA-MB-231 cells. Cells that migrated through the membrane were counted in five random fields for each group, and the relative migration rate was calculated as follows: Relative migration rate $=$ number of migrated cells/number of migrated cells in the control group. The migrated cell number in the siRNA group decreased significantly, particularly after $48 \mathrm{~h}$ of treatment (Fig. 3A). The relative migration rates of the siRNA group were significantly lower compared with those in the control and $\mathrm{NC}$ groups $(\mathrm{P}<0.001$ and $\mathrm{P}<0.0001$, respectively; Fig. 3B). The results indicated that BCSG1 lentivirus siRNA inhibited breast cancer cell migration.

Apoptosis of MDA-MB-231 cells. As shown in Fig. 4, 74.02\% of the cells in the siRNA group were Annexin V/FITC-positive, which was significantly higher compared with the $\mathrm{NC}(0.45 \%)$ and control groups $(0.84 \%)$. These results suggested that the

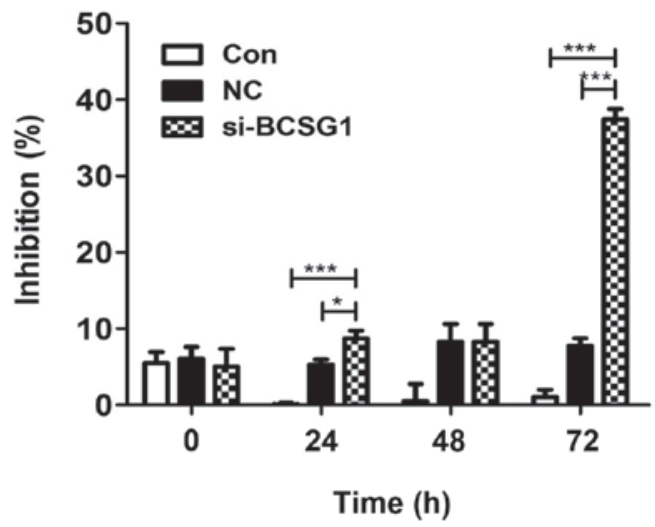

Figure 2. Cell proliferation in Cell Counting Kit-8 (CCK-8) assay at 0, 24, 48 and $72 \mathrm{~h}$ after transfection. ${ }^{*} \mathrm{P}<0.05$ and ${ }^{* * *} \mathrm{P}<0.0001$. BCSG1, breast cancerspecific gene $1 ; \mathrm{NC}$, negative control.

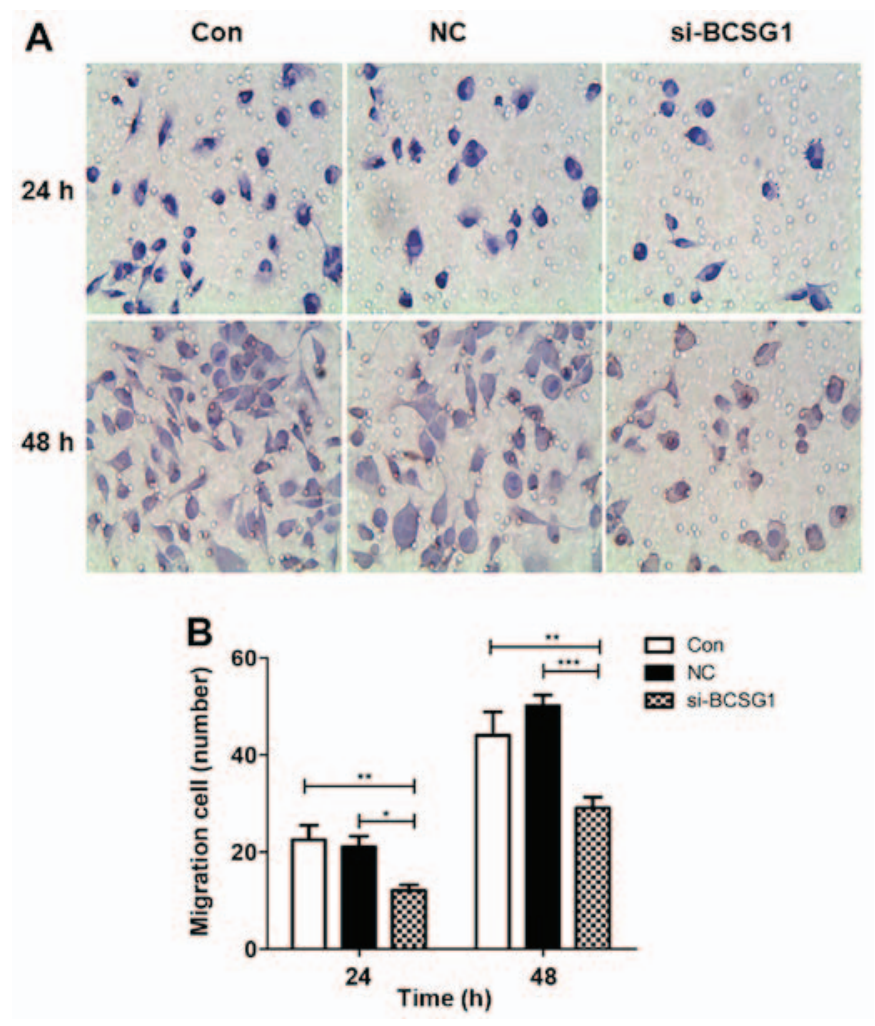

Figure 3. Migration of MDA-MB-231 cells. (A) Migration with microscopic examination. (B) Relative migration rate of three groups. ${ }^{*} \mathrm{P}<0.05,{ }^{* *} \mathrm{P}<0.001$ and ${ }^{* * *} \mathrm{P}<0.0001$. BCSG1, breast cancer-specific gene 1; NC, negative control.

BCSG1 lentivirus siRNA decreased the proliferation of breast cancer cells through induction of apoptosis.

MDA-MB-231 cell cycle. As shown in Fig. 5, a higher percentage of cells in the siRNA group $(67.25 \pm 0.93 \%)$ were in the G0/G1 phase when compared with those in the NC and control groups $(48.90 \pm 0.40 \%, \mathrm{P}<0.05$; and $50.50 \pm 0.89 \%$, $\mathrm{P}<0.05$, respectively). A lower percentage of cells in the siRNA group $(25.69 \pm 1.57 \%)$ were in the S phase. And $\sim 8.42 \pm 0.87 \%$ of cells were in the G2/M phase. These results indicated that transfection with BCSG1 lentivirus siRNA led to breast cancer cell cycle arrest. 
A

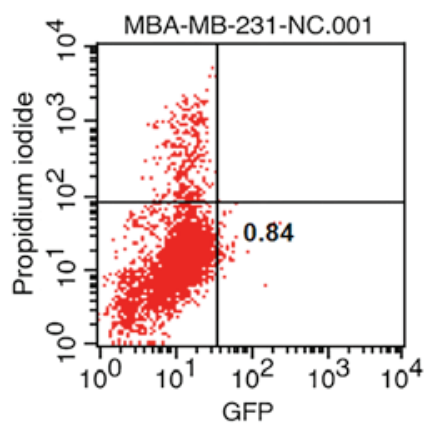

NC

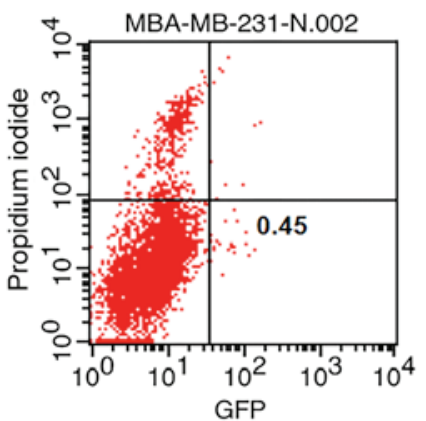

si-BCSG1

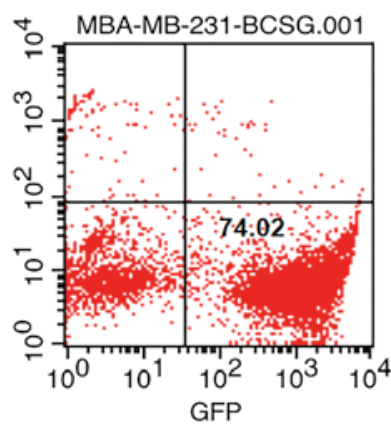

B

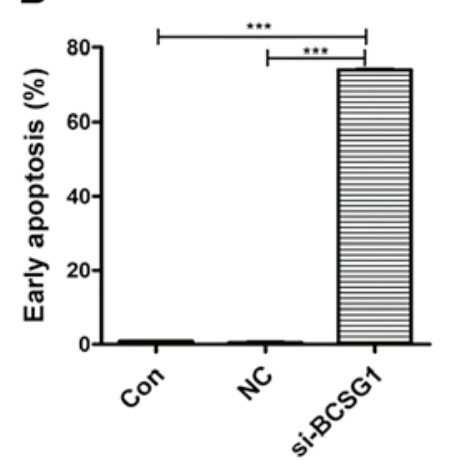

Figure 4. Apoptosis of MDA-MB-231 cells in each group. (A) Fluorescence-activated cell sorting results of the control, NC and si-BCSG1 groups. (B) Early apoptosis $(\%){ }^{* * *} \mathrm{P}<0.0001$. NC, negative control; BCSG1, breast cancer-specific gene 1; GFP, green fluorescent protein.
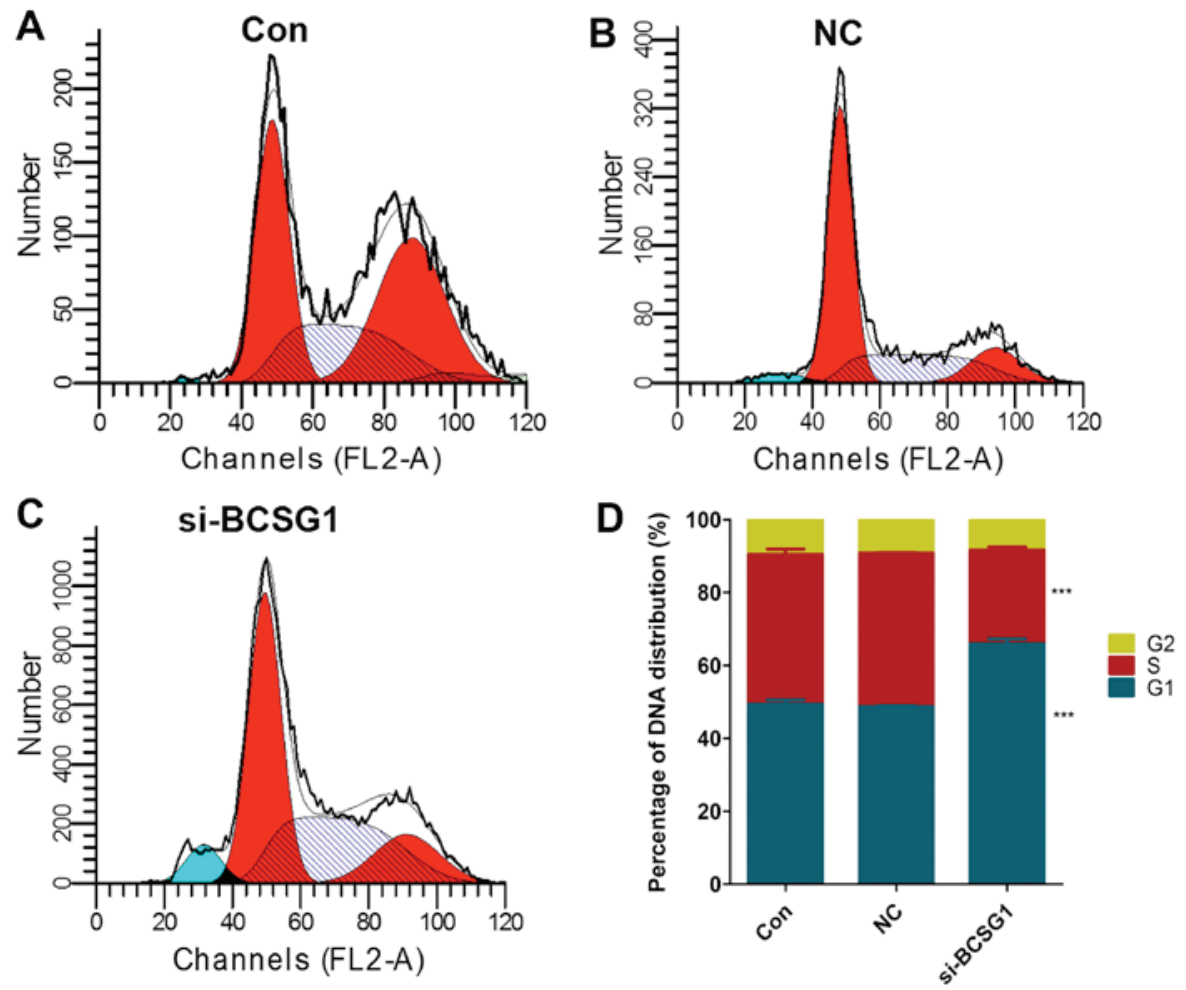

Figure 5. MDA-MB-231 cell cycle in each group. (A) Control, (B) NC and (C) si-BCSG1 groups. (D) Percentage of DNA distribution (\%). ${ }^{* * *} \mathrm{P}<0.0001 . \mathrm{NC}$ negative control; BCSG1, breast cancer-specific gene 1.
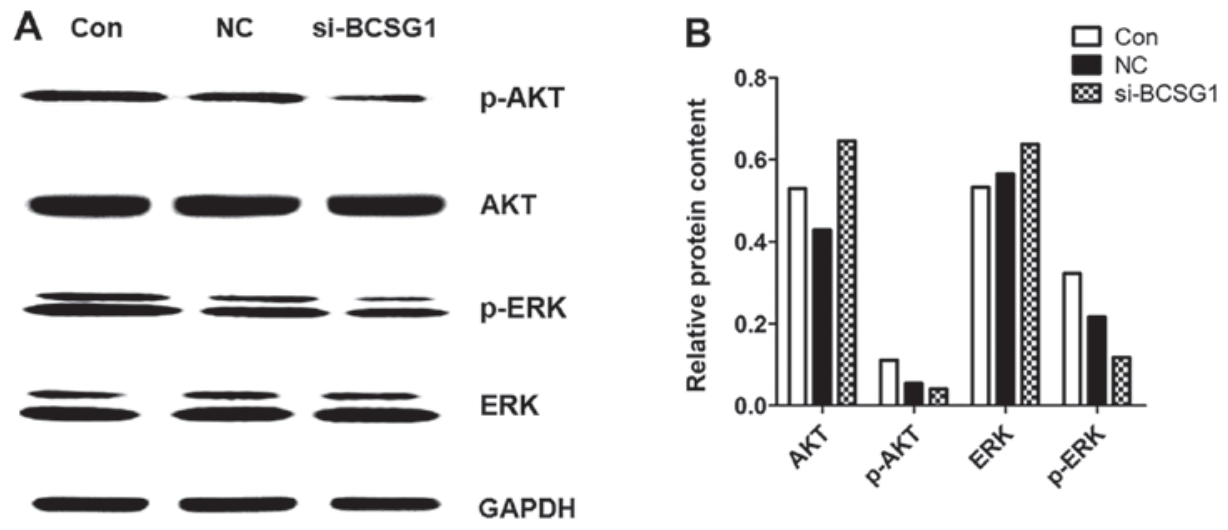

Figure 6. (A) Western blotting of AKT, p-AKT, extracellular signal-regulated kinase (ERK), p-ERK and their corresponding internal reference (GAPDH). (B) Histogram for the content of proteins in each group. NC, negative control; BCSG1, breast cancer-specific gene 1; 
Protein expression in MDA-MB-231 cells. After transfection of BCSG1 lentivirus siRNA, MDA-MB-231 cells exhibited a relative downregulation of $\mathrm{p}$-AKT and p-extracellular signal-regulated kinase (ERK) levels (Fig. 6), while there were no significant differences in the expression levels of AKT and ERK among the three groups. These data suggested that the BCSG1 lentivirus siRNA downregulated the levels of p-AKT and p-ERK, which, in turn, may be involved in the process of cell apoptosis induced by BCSG1 lentivirus siRNA.

\section{Discussion}

BCSG1, also referred to as $\gamma$-synuclein gene (SNCG), was identified by Ji et al (3) in 1997 by direct sequencing of cDNA in breast cancer. BCSG1 is not expressed in normal or benign breast tissues, but is highly expressed in advanced and metastatic breast tumors (4). Abnormal expression of BCSG1 has been implicated in various types of cancer, including ovarian, hepatic, glial tumors, esophageal, prostatic, pancreatic, colon, gastric, lung, bladder and cervical cancers $(5,20-27)$. In breast cancer, BCSG1 expression was found to be closely correlated with disease stage, lymph node involvement, metastasis, tumor size and human epidermal growth factor receptor 2 status; however, BCSG1 expression was found to be independent of the expression of estrogen receptor (ER) and progesterone receptor (28). Overexpression of BCSG1 in breast cancer cells may facilitate cell proliferation (29), increase migration and promote metastasis in nude mice (6). Moreover, BCSG1 is associated with ER $\alpha$ overexpression (30), antimicrotubule drug resistance (31), and an accelerated rate of chromosomal instability (32). All these studies suggest that BCSG1 knockdown may be an effective therapy in breast cancer treatment.

In the present study, a constructed siRNA lentiviral vector was used to effectively suppress BCSG1 expression in human breast cancer. BCSG1 mRNA expression was found to be significantly suppressed (up to 84.2\%) in MDA-MB-231 cells; cell migration and proliferation decreased significantly and the cell cycle was arrested. In accordance with our previous study, western blot analysis indicated that overexpression of BCSG1 may enhance the migration and viability of breast cancer cells through regulating the AKT and ERK pathways. In addition, the induction of apoptosis of breast cancer cells was more prominent compared with that in our previous study (74.02 vs. 33.2\%, respectively) (33). We hypothesized that this may due to prolonged expression of BCSG1 siRNA delivered by lentiviral vector in breast cancer cells.

RNAi is a powerful new tool, which may be used to perform loss-of-function genetic screens in lower organisms and may greatly facilitate the identification of components of cellular signaling pathways. In mammalian cells, such screens have been hampered by a lack of suitable tools that can be used on a large scale (34). RNAi lentiviral vectors may be a potential biological method for the short-term treatment of breast cancer.

In conclusion, our results demonstrated that BCSG1 siRNA delivered by a lentiviral vector was able to significantly reduce BCSG1 expression, suppress cell migration and proliferation and lead to cell cycle arrest; reduced protein levels of p-AKT and p-ERK may contribute to these phenomena.

\section{Acknowledgements}

The present study was funded by the Science and Technology Planning Project of Guangdong Province (grant nos. 2013B021800096, 2013B021800096 and 2014A020212038), the Shenzhen City Science and Technology Innovation International Cooperation Projects 2014 (grant no. GJHZ20140414170821180), the Basic Research Program of Shenzhen (grant nos. JCYJ 20130329110955809 and JCYJ20150330102720122) and the Science and Technology Foundation of Shenzhen (grant nos. CXZZ20150430092951135 and KQTD20140630100658078), Shenzhen City Science and Technology Innovation International Cooperation Projects 2016 (grant no. GJHZ20160301164637011) and the Natural Science Foundation of Guangdong (grant nos. 2016A030313029 and 2017A030313668).

\section{References}

1. Donepudi MS, Kondapalli K, Amos SJ and Venkanteshan P: Breast cancer statistics and markers. J Cancer Res Ther 10: 506-511, 2014.

2. Ferlay J, Soerjomataram I, Dikshit R, Eser S, Mathers C, Rebelo M, Parkin DM, Forman D and Bray F: Cancer incidence and mortality worldwide: Sources, methods and major patterns in GLOBOCAN 2012. Int J Cancer 136: E359-E386, 2015.

3. Ji H, Liu YE, Jia T, Wang M, Liu J, Xiao G, Joseph BK, Rosen C and Shi YE: Identification of a breast cancer-specific gene, BCSG1, by direct differential cDNA sequencing. Cancer Res 57: 759-764, 1997.

4. Wu K, Weng Z, Tao Q, Lin G, Wu X, Qian H, Zhang Y, Ding X, Jiang Y and Shi YE: Stage-specific expression of breast cancer-specific gene gamma-synuclein. Cancer Epidemiol Biomarkers Prev 12: 920-925, 2003

5. Bruening W, Giasson BI, Klein-Szanto AJ, Lee VM, Trojanowski JQ and Godwin AK: Synucleins are expressed in the majority of breast and ovarian carcinomas and in preneoplastic lesions of the ovary. Cancer 88: 2154-2163, 2000.

6. Jia T, Liu YE, Liu J and Shi YE: Stimulation of breast cancer invasion and metastasis by synuclein gamma. Cancer Res 59: 742-747, 1999.

7. Pan ZZ, Bruening W, Giasson BI, Lee VM and Godwin AK: Gamma-synuclein promotes cancer cell survival and inhibits stress- and chemotherapy drug-induced apoptosis by modulating MAPK pathways. J Biol Chem 277: 35050-35060, 2002.

8. Singh VK, Zhou Y, Marsh JA, Uversky VN, Forman-Kay JD, Liu J and Jia Z: Synuclein-gamma targeting peptide inhibitor that enhances sensitivity of breast cancer cells to antimicrotubule drugs. Cancer Res 67: 626-633, 2007.

9. Zhou Y, Inaba S and Liu J: Inhibition of synuclein-gamma expression increases the sensitivity of breast cancer cells to paclitaxel treatment. Int J Oncol 29: 289-295, 2006.

10. Naldini L: Lentiviruses as gene transfer agents for delivery to non-dividing cells. Curr Opin Biotechnol 9: 457-463, 1998.

11. Vodicka MA: Determinants for lentiviral infection of non-dividing cells. Somat Cell Mol Genet 26: 35-49, 2001.

12. Cockrell AS and Kafri T: Gene delivery by lentivirus vectors. Mol Biotechnol 36: 184-204, 2007.

13. Li MJ and Rossi JJ: Lentiviral vector delivery of recombinant small interfering RNA expression cassettes. Methods Enzymol 392: 218-226, 2005.

14. Dropulić B: Lentiviral vectors: Their molecular design, safety, and use in laboratory and preclinical research. Hum Gene Ther 22: 649-657, 2011 .

15. Diederichs S, Jung S, Rothenberg SM, Smolen GA, Mlody BG and Haber DA: Coexpression of argonaute-2 enhances RNA interference toward perfect match binding sites. Proc Natl Acad Sci USA 105: 9284-9289, 2008.

16. Elbashir SM, Harborth J, Lendeckel W, Yalcin A, Weber K and Tuschl T: Duplexes of 21-nucleotide RNAs mediate RNA interference in cultured mammalian cells. Nature 411: 494-498, 2001.

17. Stovall DB, Wan M, Zhang Q, Dubey P and Sui G: DNA vector-based RNA interference to study gene function in cancer. J Vis Exp 64: e4129, 2012. 
18. Sui G, Soohoo C, Affar B, Gay F, Shi Y, Forrester WC and Shi Y: A DNA vector-based RNAi technology to suppress gene expression in mammalian cells. Proc Natl Acad Sci USA 99: 5515-5520, 2002.

19. Brummelkamp TR, Bernards R and Agami R: A system for stable expression of short interfering RNAs in mammalian cells. Science 296: 550-553, 2002.

20. Liu H, Liu W, Wu Y, Zhou Y, Xue R, Luo C, Wang L, Zhao W, Jiang JD and Liu J: Loss of epigenetic control of synuclein-gamma gene as a molecular indicator of metastasis in a wide range of human cancers. Cancer Res 65: 7635-7643, 2005.

21. Lavedan C, Leroy E, Dehejia A, Buchholtz S, Dutra A, Nussbaum RL and Polymeropoulos MH: Identification, localization and characterization of the human gamma-synuclein gene. Hum Genet 103: 106-112, 1998.

22. Zhao W, Liu H, Liu W, Wu Y, Chen W, Jiang B, Zhou Y, Xue R, Luo C, Wang L, et al: Abnormal activation of the synuclein-gamma gene in hepatocellular carcinomas by epigenetic alteration. Int J Oncol 28: 1081-1088, 2006.

23. Zhou CQ, Liu S, Xue LY, Wang YH, Zhu HX, Lu N and Xu NZ: Downregulation of gamma-synuclein in human esophageal squamous cell carcinoma. World J Gastroenterol 9: 1900-1903, 2003.

24. Liu C, Guo J, Qu L, Bing D, Meng L, Wu J and Shou C: Applications of novel monoclonal antibodies specific for synuclein-gamma in evaluating its levels in sera and cancer tissues from colorectal cancer patients. Cancer Lett 269: 148-158, 2008.

25. Linhart W, Briem D, Amling M, Rueger JM and Windolf J: Mechanical failure of porous hydroxyapatite ceramics 7.5 years after implantation in the proximal tibia. Unfallchirurg 107: 154-157, 2004 (In German).

26. Iwaki H, Kageyama S, Isono T, Wakabayashi Y, Okada Y, Yoshimura K, Terai A, Arai Y, Iwamura H, Kawakita M, et al: Diagnostic potential in bladder cancer of a panel of tumor markers (calreticulin, gamma-synuclein, and catechol-O-methyltransferase) identified by proteomic analysis. Cancer Sci 95: 955-961, 2004
27. Fung KM, Rorke LB, Giasson B, Lee VM and Trojanowski JQ: Expression of alpha-, beta-, and gamma-synuclein in glial tumors and medulloblastomas. Acta Neuropathol 106: 167-175, 2003.

28. Guo J, Shou C, Meng L, Jiang B, Dong B, Yao L, Xie Y, Zhang J, Chen Y, Budman DR, et al: Neuronal protein synuclein gamma predicts poor clinical outcome in breast cancer. Int J Cancer 121: 1296-1305, 2007.

29. Jiang Y, Liu YE, Goldberg ID and Shi YE: Gamma synuclein, a novel heat-shock protein-associated chaperone, stimulates ligand-dependent estrogen receptor alpha signaling and mammary tumorigenesis. Cancer Res 64: 4539-4546, 2004

30. Jiang Y, Liu YE, Lu A, Gupta A, Goldberg ID, Liu J and Shi YE: Stimulation of estrogen receptor signaling by gamma synuclein. Cancer Res 63: 3899-3903, 2003.

31. Gupta A, Inaba S, Wong OK, Fang G and Liu J: Breast cancerspecific gene 1 interacts with the mitotic checkpoint kinase BubR1. Oncogene 22: 7593-7599, 2003.

32. Inaba S, Li C, Shi YE, Song DQ, Jiang JD and Liu J: Synuclein gamma inhibits the mitotic checkpoint function and promotes chromosomal instability of breast cancer cells. Breast Cancer Res Treat 94: 25-35, 2005.

33. He J, Xie N, Yang J, Guan H, Chen W, Wu H, Yuan Z, Wang K, Li G, Sun J, et al: siRNA-mediated suppression of Synuclein $\gamma$ inhibits MDA-MB-231 cell migration and proliferation by downregulating the phosphorylation of AKT and ERK. J Breast Cancer 17: 200-206, 2014.

34. Berns K, Hijmans EM, Mullenders J, Brummelkamp TR, Velds A, Heimerikx M, Kerkhoven RM, Madiredjo M, Nijkamp W, Weigelt B, et al: A large-scale RNAi screen in human cells identifies new components of the p53 pathway. Nature 428: 431-437, 2004. 